\title{
SKELETAL MUSCLE SATELLITE CELLS CULTURED IN SIMULATED MICROGRAVITY
}

Greg Molnar ${ }^{1}$, Nancy A. Schroedl ${ }^{1}$, Steve R. Gonda ${ }^{2}$, and Charles

R. Hartzell1

1 Department of Medical Cell Biology, Nemours Research Programs,

Alfred I. duPont Institute, Wilmington, DE 19899

and

2 Medical Sciences Division, Biotechnology Program, Johnson

Space Center, NASA Houston, Tx 77068

Corresponding Author:

Greg Molnar, Ph.D.

Department of Medical Cell Biology

Nemours Research Programs

P.O. Box 269

Wilmington, DE 19899

Phone: (302) 651-6815

FAX: (302) 651-6899

Internet: Molnar@helios.medsci.udel.edu

Running head: Satellite cells in microgravity

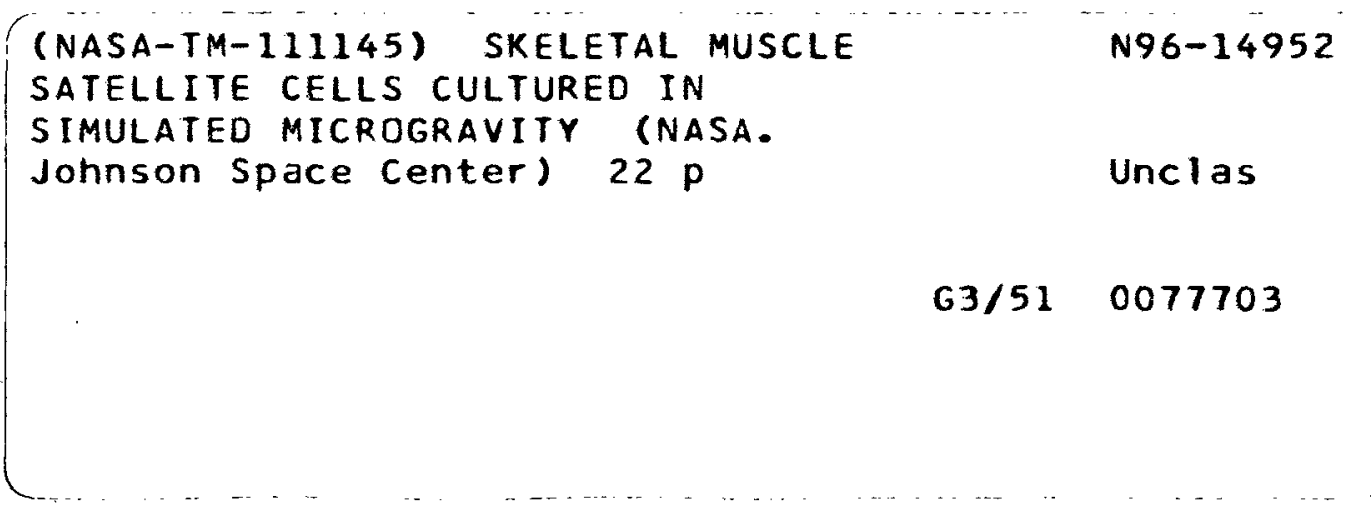




\section{SUMMARY}

Satellite cells are postnatal myoblasts responsible for providing additional nuclei to growing or regenerating muscle cells. Satellite cells retain the capacity to proliferate and differentiate in vitro and therefore provide a useful model to study postnatal muscle development. Most culture systems used to study postnatal muscle development are limited by the two-dimensional (2-D) confines of the culture dish. Limiting proliferation and differentiation of satellite cells in 2-D could potentially limit cell-cell contacts important for developing the level of organization in skeletal muscle obtained in vivo. Culturing satellite cells on microcarrier beads suspended in the High-Aspect-Ratio-Vessel (HARV) designed by NASA provides a low sheer, three-dimensional (3-D) environment to study muscle development. Primary cultures established from anterior tibialis muscles of growing rats ( $200 \mathrm{gm}$ ) were used for all studies and were composed of greater than $75 \%$ satellite cells. Different inoculation densities did not affect the proliferative potential of satellite cells in the HARV. Plating efficiency, proliferation, and glucose utilization were compared between 2-D flat culture and 3-D HARV culture. Plating efficiency (cells attached $\div$ cells plated $\times 100$ ) was similar between the two culture systems. Proliferation was reduced in HARV cultures and this reduction was apparent for both satellite cells and non- satellite cells. Furthermore, reduction in proliferation within the HARV could not be attributed to reduced substrate availability since glucose levels in media from HARV and 2-D cell culture were similar. Morphologically, microcarrier beads within the HARVS were joined together by cells into three- dimensional aggregates composed of greater than 10 beads/aggregate. Aggregation of beads did not occur in the absence of cells. Myotubes were often seen on individual beads or spanning the surface of two beads. In summary, proliferation and differentiation of satellite cells on microcarrier beads within the HARV bioreactor results in a threedimensional level of organization that could provide a more suitable model to study postnatal muscle development.

Key words: satellite cells, postnatal myogenesis, microcarrier beads, HARV bioreactor 


\section{INTRODUCTION}

Satellite cells are postnatal myogenic stem cells that provide additional nuclei to growing and regenerating muscle cells/myofibers (5). In terms of the satellite cell postnatal myogenesis involves proliferation, differentiation, and maturation $(2,10)$. Satellite cell proliferation results in daughter nuclei that can be incorporated into the myofiber or used to increase the population of satellite cells (11). Differentiation results in the satellite cell fusing with the myofiber and synthesizing muscle-specific proteins that provide for growth of the myofiber (18) and biochemically define properties associated with muscle contraction (13). Maturation involves a progressive change in the pattern of contractile protein isoforms synthesized by satellite cellderived myonuclei to a pattern more characteristic of the adult myofiber.

Although the blueprint for satellite cells to proliferate, differentiate, and form contractioncompetent myotubes is retained when cultured in vitro, the expression of contractile protein isoforms is restricted to an embryonic/fetal pattern (4). Also, myofibers often contract themselves off the dish or degenerate within $20 \mathrm{~d}$ of culture (9) and myofibers generated in two-dimensions do not morphologically resemble the parallel alignment of myofibers and the placement of connective tissue characteristic of in vivo muscle. Advanced stages of maturation have been obtained using modified culture dishes that allowed embryonic muscle cells and fibroblasts to remain in culture for up to $40 \mathrm{~d}$ (14). Long term (2-months) cultivation of embryonic muscle cells in three dimensions has been demonstrated using microcarrier beads (12). These studies suggest that three-dimensional organization of skeletal muscle can be achieved in vitro and may provide a more realistic model to represent the in vivo state.

We have developed a comprehensive research program to study muscle atrophy and regeneration. One aspect of this program is using the High-Aspect-Ratio-Vessel (HARV) to facilitate growth and differentiation of satellite cells in three-dimensions. Removing the restriction of satellite cell growth and differentiation in two-dimensions could result in muscle tissue that more closely resembles their in vivo counterpart and thus provide a better model to study muscle atrophy 
and regeneration. Description of the HARV bioreactor and conditions provided by it are detailed in a companion manuscript (1). In this study we use the HARV bioreactor to facilitate growth and differentiation of satellite cells in three dimensions; characterization of satellite cell proliferation is documented.

\section{Matrices for cell cultre}

A number of microcarrier systems are commercially available for growth of anchoragedependent cells within a suspension system. Table 1 provides information concerning two microcarrier bead types that we have successfully used to grow primary cultures of satellite cells. Our previous experience has made use of Nunc tissue culture dishes, therefore, studies presented in this paper used Nunclon biosilon beads. Both culture plates and beads were coated with a 1:100 dilution of the basement membrane extract Matrigel. Plates and beads were incubated at $37^{\circ} \mathrm{C}$ for at least $30 \mathrm{~min}$ with $2.5 \mathrm{ml}$ of 1:100 matrigel (diluted in basal medium) for $55 \mathrm{~cm}^{2}$ of surface area. Beads were gently mixed to allow equal access to Matrigel. Prior to addition of cells, culture plates and beads were washed twice in serum containing media (DMEM $+20 \%$ fetal bovine serum). Treatment of microcarrier beads with more concentrated preparations of Matrigel resulted in clumping of beads within the HARV.

\section{Methodology for culturing in HARVS}

Culture of satellite cells on microcarrier beads in the HARV bioreactor provides a low shear environment not obtained when using conventional spinner flasks to suspend microcarriers (8). By design, loading of cells, feeding, and sampling is carried out through two syringe ports built into the front face of the HARV. During feeding or sampling it is important that both syringe ports (with syringes attached) are open so that positive or negative pressure within the HARV does not develop and damage the internal oxygenation membrane. For example, loading of a $10 \mathrm{ml} \mathrm{HARV}$ is done using two- $15 \mathrm{cc}$ syringes. The plunger is removed from 1 syringe and this syringe is attached to one sampling port and another syringe-with-plunger is put on the other sampling port. 
Beads, cells, and media (are added in this order to insure that beads and cells are rinsed through by media and not left in the sampling port) are individually added to the plunger-less syringe and each component is drawn through by pulling up on the plunger of the adjacent syringe. After the vessel is filled with media, it is critical to remove all entrapped air. Following attachment to the base, movement of microcarrier beads relative to media is of paramount importance. To minimize shear, rotation of the HARV must be adjusted such that beads and fluid rotate as a solid body. For $10 \mathrm{ml}$ HARVS, we have determined that about 30 RPM approximates solid body rotation.

\section{Criteria for evaluating satellite cell proliferation in 3-D culture}

For this study, criteria used to compare growth of satellite cells in the HARV bioreactor versus flat culture plates included: 1) plating efficiency; 2) proliferation; 3) characterization of proliferating cell types; 4) glucose utilization rates; and 5) morphological examination using scanning electron microscopy. For all experiments, satellite cells were isolated from anterior. tibialis muscle of male Sprague Dawly rats (200 gms) exactly as described (6). All experiments used Dulbecco's Modified Eagles Medium (DMEM) containing $20 \%$ fetal bovine serum. The percentage of satellite cells was determined for each isolation by desmin staining using monoclonal antibody D3 reported to be specific for satellite cells (3). The D3 hybridoma was obtained from the Developmental Studies Hybridoma Bank maintained by the department of Pharmacology and Molecular Sciences, Johns Hopkins University School of Medicine, Baltimore MD, and the Department of Biological Sciences, University of Iowa, Iowa City, IA, under contract N01-HD-62915 from the NICHD. The percentage of satellite cells was determined microscopically, as the ratio of desmin positive cells to the total number of cells. Primary isolates consisted of greater than $75 \%$ satellite cells. For plating efficiency (cells attached $\div$ cells plated $\times 100$ ) 18,000 cells $/ \mathrm{cm}^{2} / 0.18 \mathrm{ml}$ media were plated onto flat cultures and microcarrier beads within the HARV. At $16 \mathrm{~h}$ a sample of beads was removed from each HARV, placed into a $0.75 \mathrm{ml}$ eppendorff tube, washed with 2-3 changes of PBS (to remove non-adherent cells) and suspended in $0.5 \mathrm{ml}$ of 0.25 $\%$ trypsin. Culture plates were rinsed twice with PBS, and $1 \mathrm{ml}$ of $0.25 \%$ trypsin was added to 
liberate cells. Following detachment, cells were counted using a hemacytometer. For HARV samples it was also necessary to calculate total number of beads so that the amount of surface area could be calculated. This was accomplished by removing 2-15 ul aliquots from each $0.5 \mathrm{ml}$ HARV sample and microscopic counting of beads in each aliquot using a $2.5 \mathrm{x}$ objective. For proliferation studies, cells were plated at $18,000 \mathrm{cells} / \mathrm{cm}^{2}$ in DMEM containing $20 \%$ fetal bovine serum. Cells were enumerated (as described above) from three $10 \mathrm{ml}$ HARVs and three $8 \mathrm{~cm}^{2}$ culture plates at $16,48,72,96$ and $120 \mathrm{~h}$. Desmin staining was used to distinguish between cell types during proliferation. For each time period cells were liberated from the surface of cell culture plates and microcarrier beads using $0.25 \%$ trypsin. Cells were enumerated using a hemacytometer and plated at equivalent densities onto Matrigel-coated culture plates. Cultures were fixed $24 \mathrm{~h}$ later and the percentage of desmin positive cells determined by cell counting. Glucose concentration was determined (using a Trinder assay kit from Sigma) on media samples $(48,72,96$, and $120 \mathrm{~h}$ ) $24 \mathrm{~h}$ after feeding fresh media. 


\section{RESULTS OF CULTURING SATELLITE CELLS IN HARV BIOREACTOR}

A characteristic of microcarrier cell culture is the ability to vary the ratio of surface area and total number of cells per volume media. Since proliferation of satellite cells is known to be affected by media conditioning, and the bioavailability of growth factors to cells within the HARV was unknown, it was essential to determine if a difference in satellite cell proliferation occurred when HARVS were inoculated with 3 different levels $\left(0.5 \times 10^{6}, 1.0 \times 10^{6}\right.$ and $\left.2.0 \times 10^{6}\right)$ of cells (Figure 1). These data indicate that: (1) changing the total number of cells within HARVS has no effect on cell proliferation, (2) increasing the total surface area $\left(27.5 \mathrm{~cm}^{2}, 55 \mathrm{~cm}^{2}\right.$ and $\left.110 \mathrm{~cm}^{2}\right)$ and associated Matrigel substratum, which is known to contain low levels of growth factors, has no effect on proliferation, and (3) attachment of cells to microcarrier beads (plating efficiency) was not affected by changing cell number and surface area within a HARV.

Plating efficiency is a function of a cell's ability to properly orient relative to the culture substratum and interact with the substratum through focal contacts . For 2-dimensional cultures, cells come in contact with the surface as a result of gravity (cells settle to the bottom of the culture plate). In contrast, rotation of cells and microcarrier beads as a solid body within the HARV occurs in three dimensions. Using equivalent cell number/surface area/volume ratios the efficiency by which satellite cells attached to microcarrier beads in the HARV bioreactor relative to flat cultures was determined (Figure 2). In addition, the fraction of myogenic (satellite cells) versus non-myogenic cells was determined by desmin staining (data not shown). The data indicate that total cells and satellite cells attach to Matrigel coated microcarrier beads suspended in the HARV with the same efficiency as cells plated onto flat culture dishes. Cells remaining unattached after $18 \mathrm{~h}$ fail to attach when replated for an additional $24 \mathrm{~h}$.

The proliferative potential of satellite cells was compared between flat cultures and HARV cultures. Satellite cells $\left(1.0 \times 10^{6}\right)$ were inoculated at a ratio of 20 cells/microcarrier bead. A similar number of cells $/ \mathrm{cm}^{2}$ surface area/volume media was established in two-dimensional cultures. The number of cells $/ \mathrm{mm}^{2}$ was determined at $16,48,72,96$ and $120 \mathrm{~h}$ for HARV and flat 
cultures (Figure 3A). Figure 3B illustrates the proliferative curve generated in Figure 3A when myogenic and non-myogenic cell types are individually analyzed. These data suggest that cell proliferation is reduced for myogenic and non-myogenic cell types cultured in the HARV relative to flat culture. Reduced proliferation of cells within the HARV bioreactor does not result from reduced substrate (glucose) availability (Figure 4). Finally, reduction in proliferation of satellite cells between 48 and 72 h coincides with the onset of myotube formation in flat cultures. 


\section{DISCUSSION AND FUTURE PROSPECT}

In this study satellite cells (postnatal myoblasts) were collected from growing rats, and cultured within the HARV bioreator. Unlike conventional spinner flasks, the HARV bioreactor provides a low shear, three-dimensional environment for the suspension of cells attached to microcarrier beads. Our goal is to utilize the advantage of the quiescent environment provided by the HARV bioreactor to study postnatal myogenesis in the absence of constraints put forth by twodimensional culture dishes. Towards this end we have demonstrated that primary cultures of rat satellite cells can proliferate, differentiate into myotubes, and form three-dimensional aggregates within the HARV bioreactor.

The majority of data presented herein have dealt with the characterization of satellite cell proliferation within the HARV bioreactor. Proliferation was compared between satellite cells cultured in the HARV and satellite cells cultured on two-dimensional culture dishes. Proliferation of satellite cells within the HARV was not changed by increasing either the number of cells and/or the total surface area within the HARV. These results suggest that the microenvironment surrounding individual cells attached to a microcarrier bead which includes nutrient exchange, nutrient availability, waste material build up, cell-to-cell contact, and media conditioning, was not affected by changing the total number of cells and the available surface area (microcarriers) within a $10 \mathrm{ml}$ HARV. The inoculation density reported in previous experiments conducted in the HARV was 200,000 cells $/ \mathrm{ml}$ (7). The ability of satellite cells to proliferate equally well at $50,000 \mathrm{cells} / \mathrm{ml}$ versus 200,000 cells $/ \mathrm{ml}$ within the HARV provides more flexibility for studies designed to evaluate the proliferative phase of myogenesis. For example, our future experimental goals is to characterize the role of IGF 1, FGF and TGF $B$ on satellite cell proliferation in three dimensions.

Satellite cells require attachment to substratum prior to proliferation. For two dimensional cell culture, cells settle to the bottom of the culture dish under the force of gravity and contact the substratum by default. In contrast, contact of satellite cells with microcarrier beads suspended within the HARV bioreactor represents a more dynamic process. Thus, it was somewhat surprising that there was no difference in plating efficiency between HARV cultures and flat two- 
dimensional cultures. In addition, microscopic observation of stained preparations of cells attached to microcarrier beads after $18 \mathrm{~h}$ of culture showed that the number of cells per bead was relatively uniform. Using desmin to distinguish satellite cells from non-satellite cells, no difference in the efficiency of attachment for either cell type was evident in two dimensional culture versus the HARV bioreactor. With demonstrated equivalent plating efficiencies, equivalent inoculation densities can be used in subsequent studies when comparing proliferation of satellite cells between two-dimensional cell culture and the HARV.

Proliferation of satellite cells and non-satellite cells was decreased in the HARV bioreactor relative to two-dimensional culture plates. Cell proliferation is primarily controlled by growth factor levels in the media (16). Since we previously demonstrated that cells proliferate equally at different densities within the HARV, it seems unlikely that levels of growth factors or substrates in the culture medium were limiting, and could account for decreased proliferation of cells in the HARV. This contention is supported by the finding that similar glucose levels were found for both HARV and flat cultures. Although the levels of factors/nutrients may not differ, the ability to respond to, or be presented with the factors, may differ between cells in flat culture versus cells growing on microcarrier beads suspended within the HARV. A second explanation for differences in proliferation is that cells suspended on microcarrier beads within the HARV would be exposed to more shear, relative to cells in flat cultures. Decrease proliferation for some cell types in the presence of measured shear has been reported (8). Finally, formation of cellular aggregates on microcarrier beads adds a layer of complexity to cells cultured within the HARV. As early as $48 \mathrm{~h}$, aggregates of beads bridged together by cells are forming. Thus, a logical question is whether cells actively involved in the formation of three dimensional aggregates, are able to proliferate at the same rate as cells on the surface of microcarriers not involved in aggregate formation. If not, the population of cells capable of proliferating would be decreased in the HARV due to their participation in aggregate formation. 
In summary, we have demonstrated that satellite cells can proliferate and differentiate on microcarrier beads suspended in the HARV bioreactor. It is our desire to use the HARV to facilitate the formation of three dimensional skeletal muscle from mononucleated satellite cells. The criteria for success using the HARV bioreactor will be how closely muscle tissue derived from satellite cells in the HARV mimics the situation in vivo. 


\section{ACKNOWLEDGEMENTS}

We would like to thank John Holsheik for his assistance with electron microscopy; Dr. Rob Akins for helpful discussions and Karla-Anne for her help in preparaing the manuscript. This work was supported by NASA grant NAG 9-656 (CRH, NAS, SRG). 


\section{References}

1. Akins, R. E.; Schroedl, N.A.; Gonda, S.R.; Hartzell, C.R. Neonatal rat heart cells cultured in simulated microgravity. In Vitro Cell. Dev. Biol. (This issue).

2. Allen, R.E.; Merkel , R.A.; Young, R.B. Cellular aspects of muscle growth: Myogenic cell proliferation. J. Animal Science 49: 115-127; 1979.

3. Allen, R. E.; Rankin, L. L.; Greene, E. A.; Boxhorn, L. K.; Johnson, S. E.; Taylor, R. G.; Pierce, P. R. Desmin is present in proliferating rat muscle satellite cells but not in bovine muscle satellite cells. J. Cellular Physiology 149: 525-535; 1991.

4. Bandman, E.; Matsuda, R.; Strohman, R.C. Developmental appearance of myosin heavy and light chain isoforms in vivo and in vitro in chicken skeletal muscle. Dev. Biol. 93:508-518; 1982.

5. Campion D.R. The muscle satellite cell: a review. Int. Rev. Cytol. 87: 225-251; 1984.

6. Dusterhoft, S.; Pette, D. Satellite cells from rat express slow myosin under appropriate culture conditions. Differentiation 53, 25-33; 1993.

7. Goodwin T.J.; Jessup J.M.; Wolf D.A. Morphologic differentiation of colon carcinoma cell lines HT-29 and HT-29KM in rotating-wall vessels. In Vitro cell. Dev. Biol. 28A:47-60; 1992.

8. Goodwin T.J.; Prewett T.L.; Wolf D.A.; Spaulding, G.F. Reduced shear stress: A major component in the ability of mammalian tissues to form three-dimensional assemblies in simulated microgravity. J. Cellular Biochemistry 51: 301-311.; 1993.

9. Molnar, G.; Dodson, M. V. Characterization of sheep semimembranosus muscle and associated satellite cells: expression of fast and slow myosin heavy chain. Basic and Applied Myology. 2: 183-190; 1992.

10. Molnar, G.; Dodson, M.V. Satellite cells isolated from sheep skeletal muscle are not homogeneous. Basic and Applied Myology. 3: 173-180; 1993. 
11. Moss F.P.; Leblond C.P. Satellite cells as the source of nuclei in muscles of growing rats. Anat. Rec. 170: 421-436; 1970.

12. Shahar, A.; Reuveny, S.; Zhang, M.; Monteros, E.; Vellis, J.; Shanberg, A. Differentiation of myoblasts and CNS cells grown either separately or as co-cultures on microcarriers.

Cytotechnology 9: 107-115; 1992.

13. Staron R.S. Correlation between myofibrillar ATPase activity and myosin heavy chain composition in single human muscle fibers. Histochemistry 96: 21-24; 1991.

14. Strohman, R.C.; Bayne, E.; Spector, D.; Obinata, T.; Eastwood, J. M.; Maniotis, A. Myogenesis and histogenesis of skeletal muscle on flexible membranes in vitro. In Vitro Cell. Dev. Biol. 26: 201-208; 1990.

15. Tischler M.E.; Henriksen E.J.; Munoz K.A.; Stump C.S.; Woodman C.R.; Kirby C. R. Spaceflight on STS-48 and earth-based unweighting produce similar effects on skeletal muscle of young rats. J. Appl. Physiol. 74(5): 2161-2165; 1993.

16. White T.P.; Esser, K.A. Satellite cell and growth factor involvement in skeletal muscle growth. Medicine and Science in Sports and Exercise. 21: S158-S163; 1989.

17. Winchester P.K.; Gonyea W. J. A quantitative study of satellite cells and myonuclei in stretched avian slow tonic muscle. Anatomical Record 232: 369-377; 1992.

18. Young R. B.; Miller, T. R.; Merkel, R. A. Myofibrillar protein synthesis and assembly in satellite cell cultures isolated from skeletal muscle of mice. J. Animal Science 48: 54-62; 1979. 


\section{FIGURE LEGENDS}

Figure 1. Effect of cell number and surface area on cell proliferation. Three $10 \mathrm{ml} \mathrm{HARVs}$ were inoculated with $\left(0.5 \times 10^{6}, 1.0 \times 10^{6}\right.$ and $\left.2.0 \times 10^{6}\right)$ different levels of cells and appropriate levels of substratum $\left(27.5 \mathrm{~cm}^{2}, 55 \mathrm{~cm}^{2}\right.$, and $\left.110 \mathrm{~cm}^{2}\right)$ to maintain the ratio of cells/bead at $20: 1$. The number of cells/bead was determined at the indicated times by microscopic counting. Each data point represents the mean $+/$ - the standard error for three experiments (1 replicate/experiment).

Figure 2. Plating efficiency (cells attached $\div$ cells plated $x 100$ ) of satellite cells in two-dimensional culture dishes and microcarrier beads suspended in the HARV bioreactor was determined $18 \mathrm{~h}$ after initial plating. Data is presented as the mean $+/-$ the standard error for 3 experiments ( 3 replicates/experiment).

Figure 3A. Proliferation of cells was compared in two-dimensional culture dishes and microcarrier beads suspended in the HARV bioreactor. (B). Desmin staining was used to distinguish between myogenic and non-myogenic cell types during proliferation. For each time period cells were liberated from the surface of cell culture plates or microcarrier beads. Cells were counted and plated at equivalent densities onto Matrigel-coated culture plates. Cultures were fixed $24 \mathrm{~h}$ later and the percentage of desmin positive cells determined by cell counting.

Figure 4. Glucose level [mg/dl] in $10 \mathrm{ul}$ of media from HARVS and cell cultures was determined at times indicated. Mean values \pm standard error from 2 experiments ( 2 replicates/experiment) are presented.

Figure 5. Scanning electron micrographs showing 3-dimensional aggregation of microcarrier beads with cells on surface (A, bar =100 um) and satellite cell-derived myotube spanning the surface of a single bead $(B$, bar $=10 \mathrm{um})$. 
Figure 5. Scanning electron micrographs showing 3-dimensional aggregation of microcarrier beads with cells on surface (A, bar $=100 \mathrm{um}$ ) and satellite cell-derived myotube spanning the surface of a single bead $(B, b a r=10 u m)$. 
Table 1: COMPARISON OF MICROCARRIERS

\begin{tabular}{|c|c|c|}
\hline SPECIFICATIONS & CYTODEX-3 & BIOSILON \\
\hline Bead composition & Cross-linked dextran & Polystyrene \\
\hline Density & $1.04 \mathrm{~g} / \mathrm{cc}$ & $1.05 \mathrm{~g} / \mathrm{cc}$ \\
\hline Diameter & $133-215$ microns & $160-300 \mathrm{microns}$ \\
\hline Surface area & $4600 \mathrm{~cm}^{2} / \mathrm{gm} \mathrm{dry} \mathrm{weight}$ & $255 \mathrm{~cm}^{2} / \mathrm{gm}$ \\
\hline \# beads/g dry weight & $4.0 \times 10^{6}$ & $2.41 \times 10^{5}$ \\
\hline Surface layer & Gelatin (type I collagen) & Nunclon $\Delta$ \\
\hline
\end{tabular}



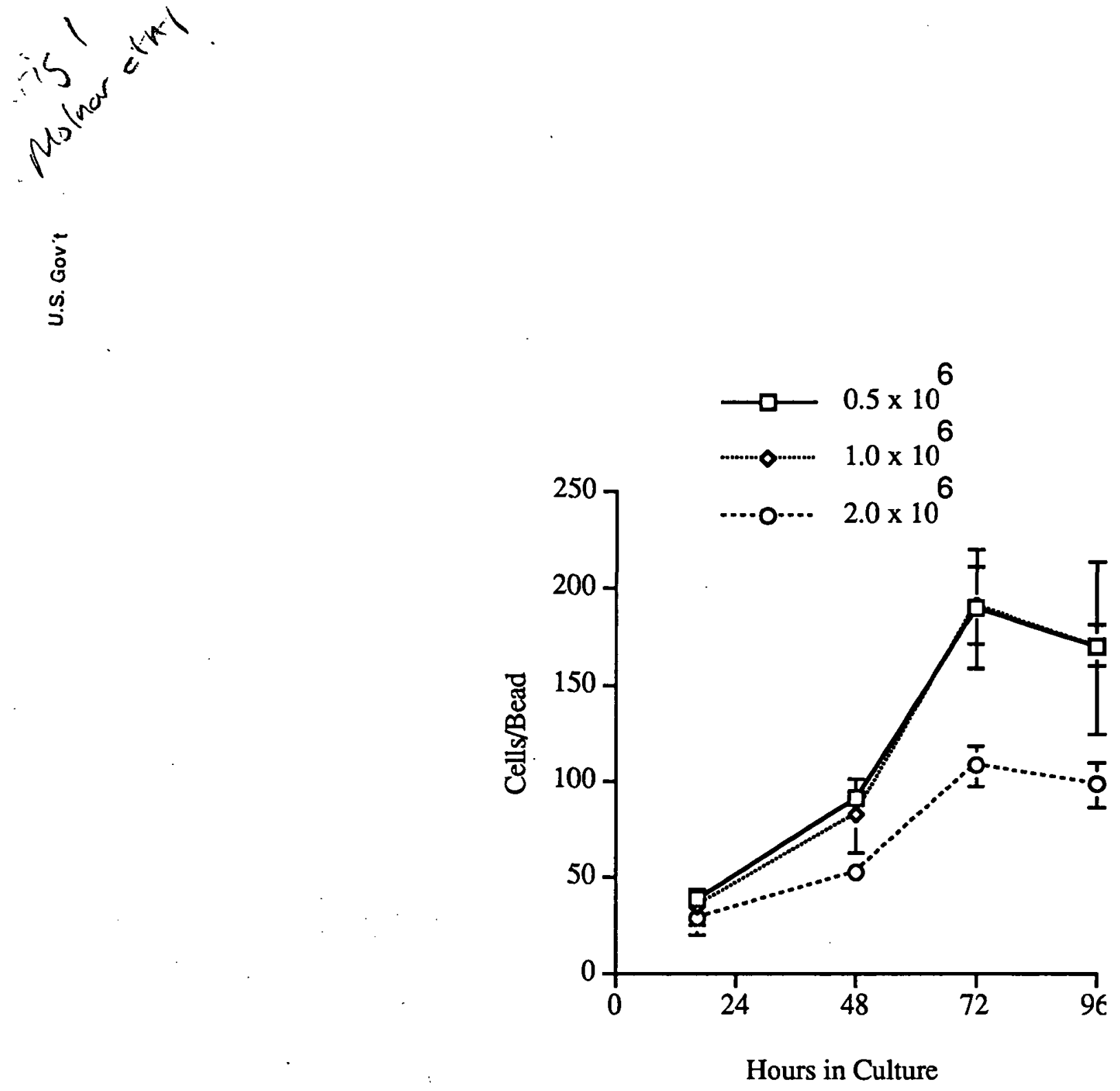
Dे
0
0
0

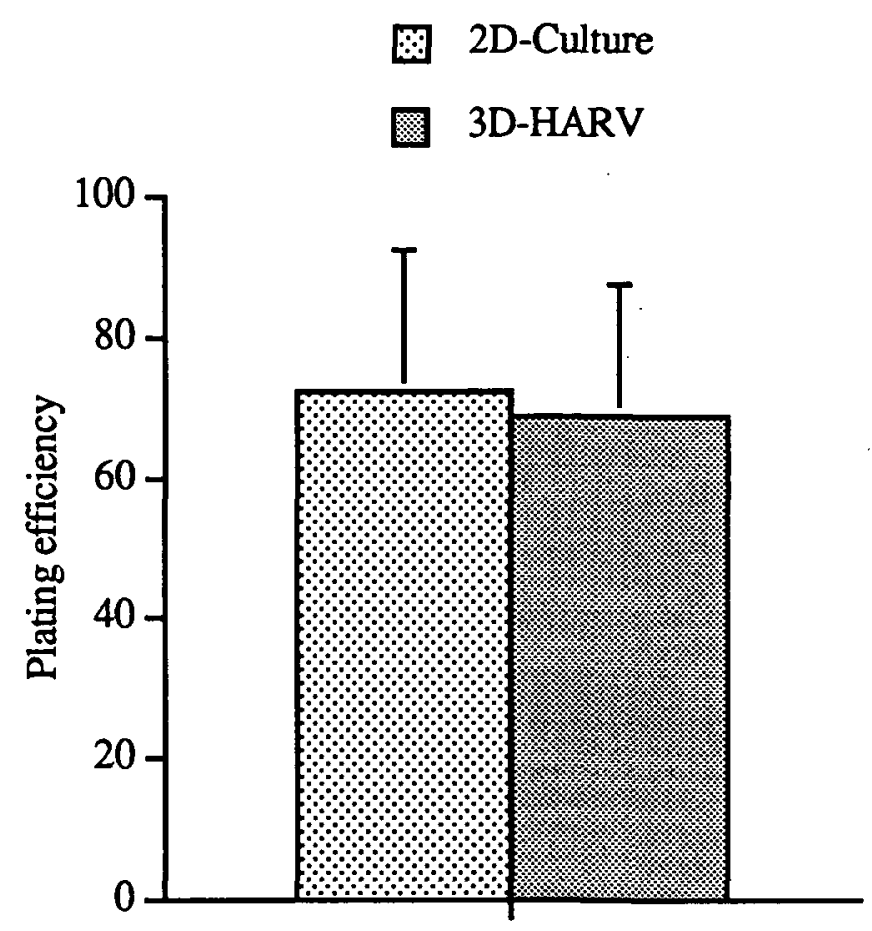


A

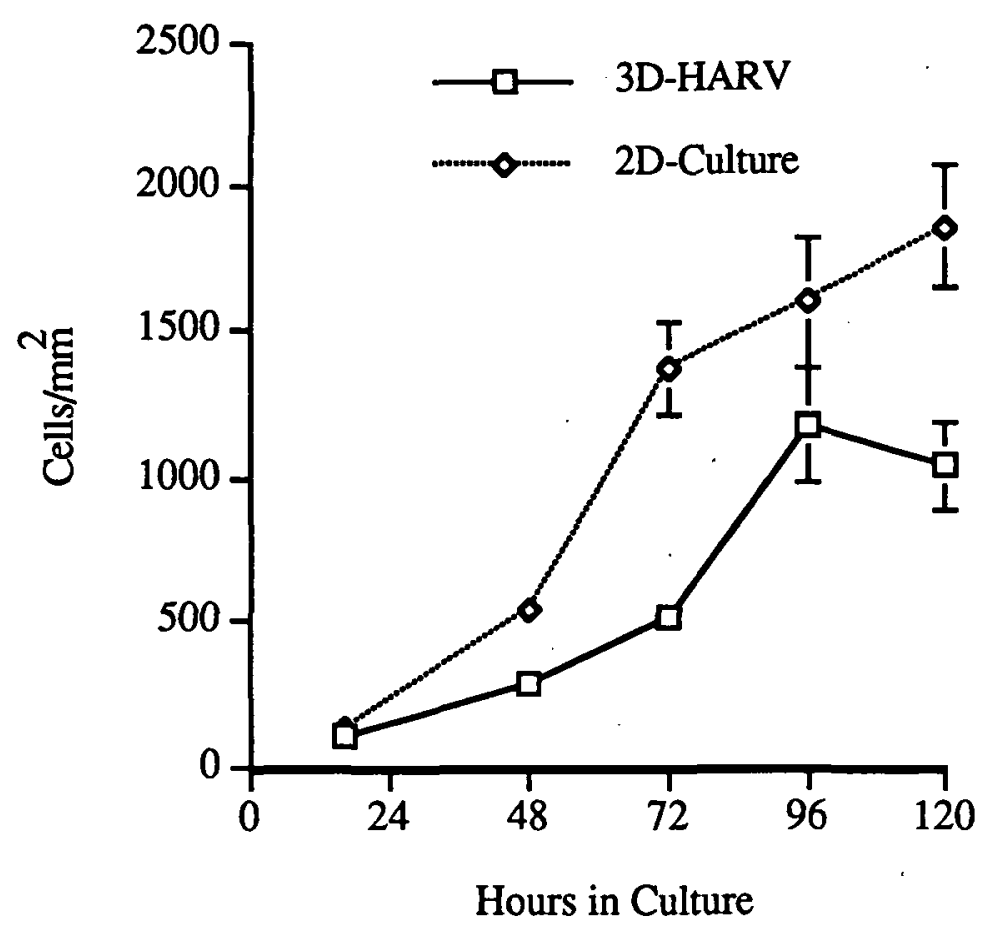

B

$\longrightarrow$ Myogenic 3D-HARV

Myogenic 2D-Culture

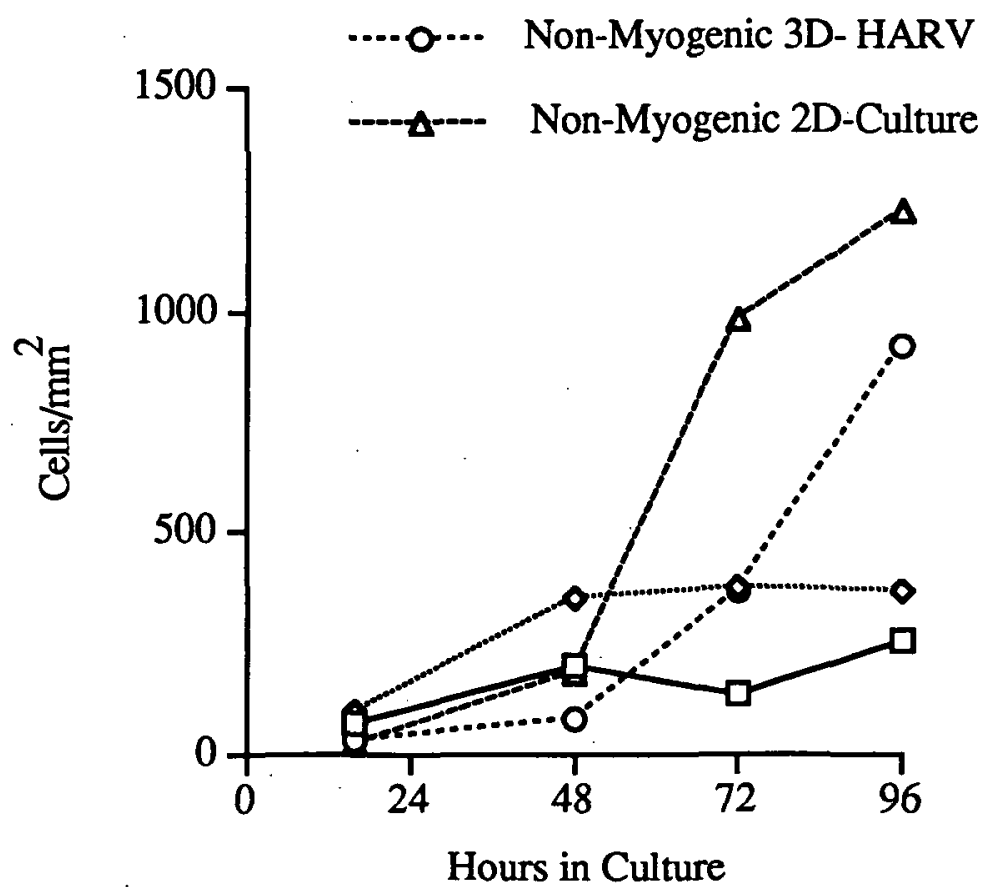




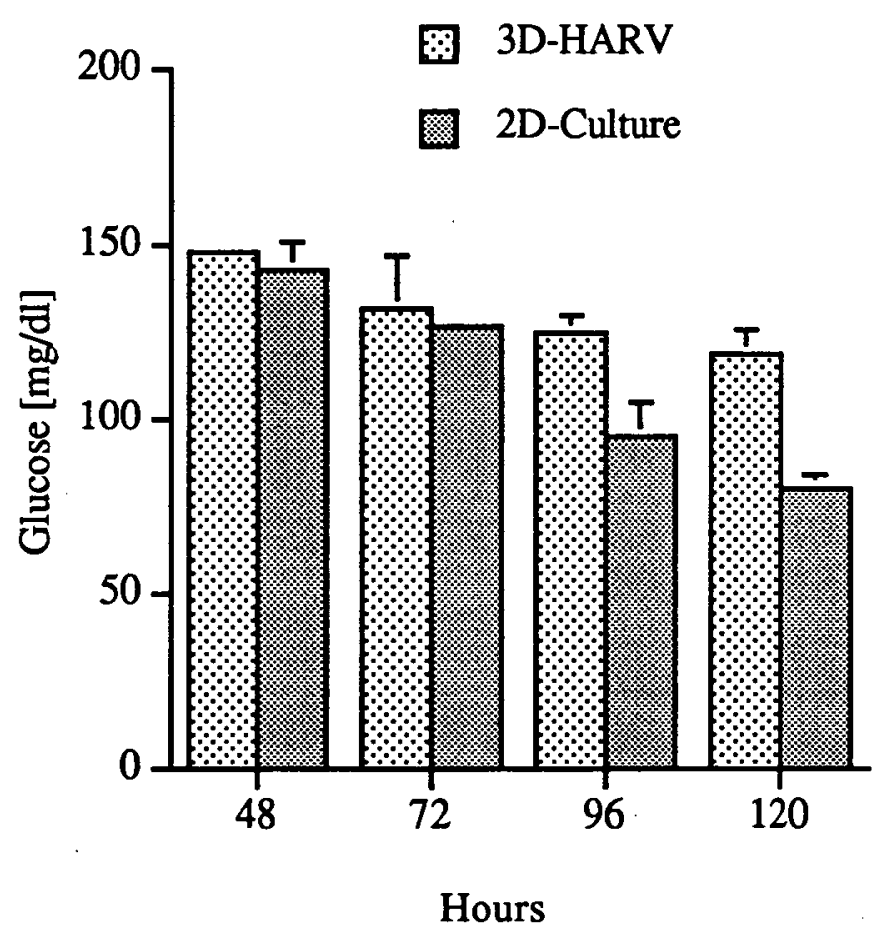



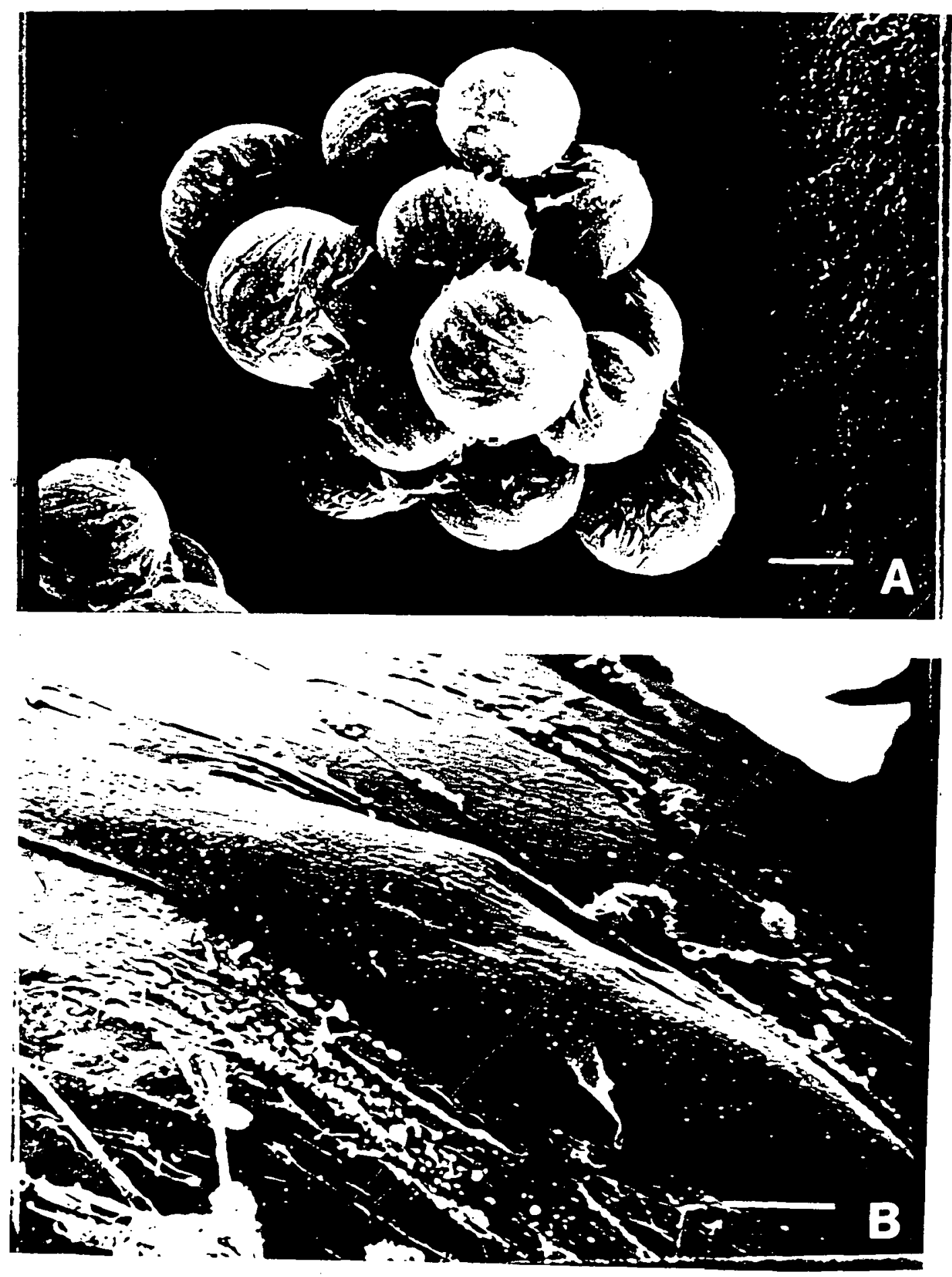